\title{
Does the Comprehensive two-Child Policy Help Improve the Financial Sustainability of Individual Accounts of Basic Pension in China?
}

\author{
Lizhen Huang $^{1 *}$, Xiaohua Chen ${ }^{2}$ \\ ${ }^{\mathrm{T}}$ College of Mathematics and Physics, Wenzhou University, Wenzhou, Zhejiang, China \\ ${ }^{2}$ School of Insurance, Central University of Finance and Economics, Beijing, China
}

\section{*Corresponding Author}

Lizhen Huang

\section{Article History}

Received: 16.10 .2020

Accepted: 02.11.2020

Published: 09.11.2020

\begin{abstract}
The Chinese government has implemented the comprehensive two-child policy in 2016, but can this policy really improve the financial sustainability of individual accounts in China's basic pension? This research designs five possible schemes of China's total fertility rate affected by the comprehensive two-child policy to explore the impact of the policy on the financial status of individual accounts of China's basic pension. The results show that (1) the impact of the comprehensive two-child policy on the financial status of individual accounts has a time lag, and the earliest year that the policy works is 2041. (2) On the whole, if the comprehensive two-child policy increases China's future total fertility rate, this policy will help improve the sustainable operation ability of individual accounts in most years of the forecast period. And the mode of increasing the total fertility rate under the middle level scheme will help improve the sustainable operation ability of individual accounts in the years after the policy works.
\end{abstract}

Keywords: Pension; fertility policy; individual accounts; financial effect.

\section{INTRODUCTION}

At present, China's population is aging at a high level and its aging rate is fast, making the sustainability of basic pension face a severe situation. Many scholars (Yang and Shi [1]; Tian and Zhao [2]; Zhao et al., [3]; Chen and Yang [4]; Chen et al., [5]; Chen [6]; etc.) believe that the sustainable of China's basic pension will face serious challenges in future. According to the China Statistical Yearbook 2019, we can see the change trend of the proportion of the population of each age group in the total population from 1997 to 2018 . Among them, the proportion of people aged 65 and above in the total population is rising rapidly, from $6.5 \%$ at the end of 1997 to $11.9 \%$ at the end of 2018 , with an average annual growth rate of $2.92 \%$, which shows that China is accelerating into an aging society. Similarly, according to the China Statistical Yearbook 2019, it can be known that the contribution incomes of the basic pension fund for urban employees in Liaoning, Heilongjiang, Hubei, and Qinghai provinces of China in 2018 has not offset its pension expenditures. Where the financial situation of Heilongjiang Province is particularly severe, and the accumulative deficit has reached -57.72 billion Yuan. It can be seen that the financial sustainability of the basic pension for urban employees in China has faced severe challenges.

The financial accounts of China's basic pension include two types of accounts, one is the social pooling accounts, and the other is the employee's individual accounts. The individual accounts, established in the document of “Decision on Establishing a Unified Basic Pension System for Enterprise Employees', i.e. State Council Document 26 in 1997, is an important part of China's basic pension system. Under individual accounts system, the employees who pay more for themselves will get higher pension when they retire, which will encourage them to participate in the basic pension system. The individual accounts pension is equivalent to the government's debt to the insured employees. When the employees retire, the government needs to pay them the pension on time and in full. Thus, the sustainable operation of individual accounts is closely related to whether the pension benefits of the insured persons can be ensured. At present, the increasingly serious aging of the population will also bring severe challenges to the sustainable operation of

Copyright $\odot 2020$ The Author(s): This is an open-access article distributed under the terms of the Creative Commons Attribution 4.0 International License (CC BY-NC 4.0) which permits unrestricted use, distribution, and reproduction in any medium for noncommercial use provided the original author and source are credited. 
individual accounts. The Chinese government needs to pay more attention to the financial situation of individual accounts.

To actively respond to the aging population, the Chinese government implemented the comprehensive two-child policy in January 2016. The comprehensive two-child policy will affect China's total fertility rate in the future, and affect the future insured population structure. Thus, it is necessary to conduct in-depth research on whether the comprehensive two-child policy can help to improve the financial sustainable operation ability of individual accounts for China's basic pension.

Some literatures have discussed the influence of birth policy on pension finance. Luo et al., [7] measured the impact of demographic factors on the incomes and expenditures of basic pension and individual accounts pension, and believed that the increase of fertility rate by age of women of childbearing age and the increase of retirement age of employees are conducive to the balance of fund revenues and expenditures. Sun et al., [8] simulated the development trend of urban basic pension gap under different family planning policy adjustment programs, and believed that gradually liberating the two child birth policy is conducive to improving the financial sustainability of the pension system. Zeng et al., [9] simulated the impact of the comprehensive two-child policy on the basic pension fund of urban and rural residents, and believed that this policy could ease the payment pressure of the basic pension fund. Xiao and Deng [10] built an actuarial model to simulate the impact of the comprehensive two-child policy on the financial performance of the urban employees' basic pension fund. They believed that although the policy could not delay the time when the current balance of the fund was in deficit, it could effectively relieve the future fund payment pressure. By building an actuarial model, Li and Luo [11] simulated the financial situation and change trend of the basic pension fund for urban employees in Shanghai. They believed that the comprehensive two-child policy could not reverse the trend that the incomes of the fund could not offset its expenditures, and it was also difficult to restrain the trend of expanding pension gap. Although these literatures have discussed the impact of fertility policy on China's pension finance, they have not specifically focused on the impact of fertility policy on individual accounts' finance of the basic pension in China. This paper will explore the impact of the comprehensive two-child policy, whether it can help to improve the financial sustainable operation ability of individual accounts of basic pension in China

\section{THE DESIGN OF THE IMPACT SCHEME OF THE COMPREHENSIVE TWO-CHILD POLICY}

In 2019, based on the historical data of China's total fertility rate and the background of the implementation of the comprehensive two-child policy in 2016, the United Nations Population Division predicted China's future total fertility rate, and obtained China's total fertility rate at low, medium and high levels.

The total fertility rate of low-middle level scheme is set between the total fertility rate of low level scheme and middle level scheme, and the total fertility rate of middle-high level scheme is set between middle scheme and high level scheme. On this basis, five schemes of total fertility rate can be set up, including low level scheme, low-middle level scheme, middle level scheme, middle-high level scheme and high level scheme, as shown in Figure-1. China's total fertility rate without considering the comprehensive two-child policy is taken as the baseline situation. According to the United Nations Population Division's forecast of China's total fertility rate, it can be seen that the baseline total fertility rate during the forecast period will remain at the level of 1.69 in 2019.

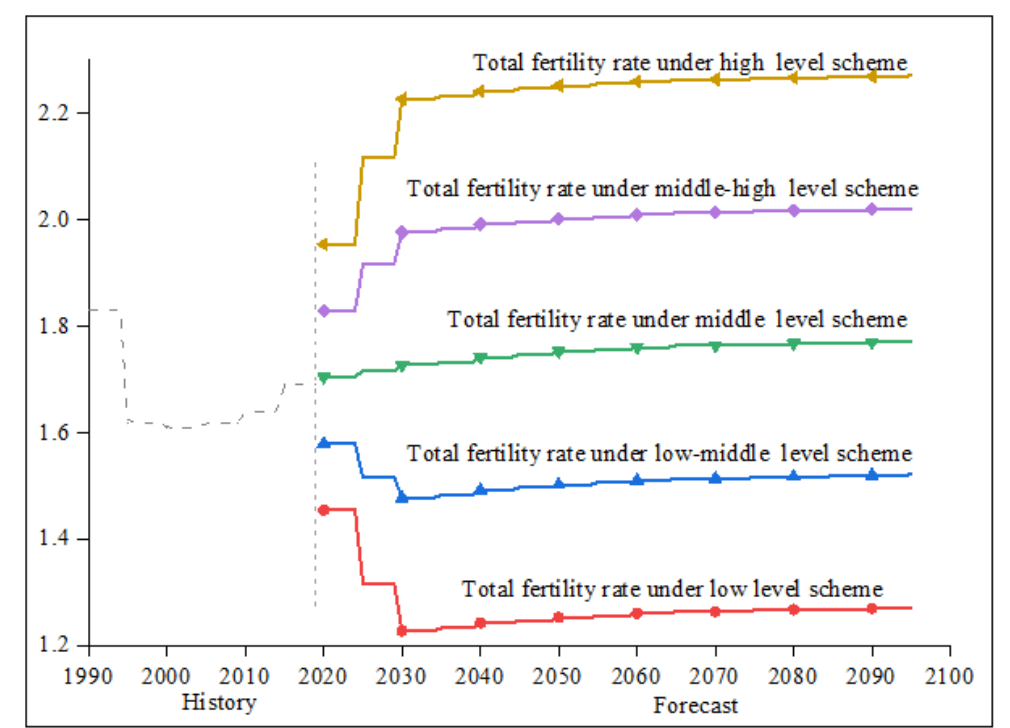

Fig-1: Five possible impact schemes of the policy on China's total fertility rate 


\section{THE MODEL OF PENSION INCOMES AND EXPENDITURES OF INDIVIDUAL ACCOUNTS \\ Pension Incomes of Individual Accounts}

The contribution incomes of individual accounts of basic pension $C_{t}$ is the endowment insurance premium paid by individual insured employees. According to the provisions of the State Council Document 26 in 1997, and with reference to Yang and Shi [1], Chen and Yang [4], and Chen [6], it can be seen that the $C_{t}$ formula is

$$
C_{t}=c \cdot \sum_{x=e}^{r-1} L_{t, x} \cdot S_{t-1, x-1}
$$

Where the $c$ is the contribution rate of individual accounts, the $e$ is age at which employees get their first job and participate in basic pension insurance, and $r$ is the retirement age of employees. $L_{t, x}$ refers to the number of employees in the basic pension insurance of enterprise employees aged $x$ in year $t . S_{t, x}$ is the wage of the on-the-job employee at the age of $x$ in year $t$.

In addition, $S_{t, x}=(1+s) \cdot S_{t, x-1}=\cdots=(1+s)^{x-e} \cdot S_{t, e}$ and $S_{t, x}=\left(1+g_{t}\right) \cdot S_{t-1, x-1}$, the $S_{t, e}$ is the salary level of new entrants in year $t$. The $s$ is the growth rate of seniority wage, and the $g_{t}$ is wage growth rate in year $t$. Thus, $S_{t, x}$ can be calculated for each year during the forecast period.

\section{Pension Expenditures of Individual Accounts}

According to the State Council Document 26 in 1997, the government only needs to pay the individual accounts pension expenditures for the "middle-persons" and "new-persons". The "middle-persons" refer to the insureds who entered the job before the implementation of the document (the State Council Document 26 in 1997) and retired after the implementation of this document. The "new-persons" refer to the insureds who entered the job after the implementation of the document. And the $z$ is the starting year of the implementation of the State Council Document 26 in 1997, that is, $z=1997$.

\section{Pension Expenditures for the "Middle-Persons"}

The age range of the retired "middle-persons" is $[r, r+t-z-1]$ years old. When the retired "new-persons" appear, that is, $t \geq z+2+l_{m}$, the age range of the retired "middle-persons" becomes $\left[r+t-z-1-l_{m}, r+t-z-1\right]$ years old, where $l_{m}=r-e-1$. Thus, the age range can be recorded as $\left[\max \left(r, r+t-z-1-l_{m}\right), r+t-z-1\right]$ years old. The pension expenditures $P_{t}^{M}$ of the individual accounts for the retired "middle-persons" is:

$$
P_{t}^{M}=\sum_{x=\max \left(r, r+t-z-1-l_{m}\right)}^{r+t-z-1} L_{t, x} \cdot I_{t, x}
$$

Where the $m_{r}$ is the number of months of individual accounts pension that should be paid to retirees. According to the provisions of the State Council Document 26 in 1997 and referring to the methods of Yang and Shi [1], Chen and Yang [4], and Chen [6], then the expenditure $I_{t, x}$ is

$$
I_{t, x}=I_{t-(x-r), r}=\frac{12}{m_{r}} \times \sum_{k=\max \left(z, t-(x-r)-1-l_{m}\right)}^{t-(x-r)-1}\left[c_{k} S_{k-1, x+(k-1)-t} \cdot \prod_{h=k+1}^{t-(x-r)}\left(1+j_{h}\right)\right]
$$

\section{Pension Expenditures for the "New-Persons"}

The age range of the retired "new-persons" is $\left[r, r+t-z-1-l_{m}-1\right]$ years old, which is $[r, t-z+e-1]$ years old. As the years go on, the "new-persons" will constantly replace the "middle-persons". When $t \geq z-e+\omega+1$, all the retirees are "new-persons", and the "middle-persons" has disappeared. The pension expenditures $P_{t}^{N}$ of the individual accounts for the retired "new -persons" is:

$$
P_{t}^{N}=\sum_{x=r}^{t-z+e-1} L_{t, x} \cdot I_{t, x}
$$

Where the $I_{t, x}$ are consistent with the corresponding formula (3) of pension expenditures for "middle-persons".

Therefore, the basic pension expenditures of individual accounts for enterprise retirees are equal to the sum of basic pension expenditures of individual accounts for "middle-persons" and "new-persons": $P_{t}=P_{t}^{M}+P_{t}^{N}$. 


\section{ESTIMATION OF MODEL PARAMETERS}

Estimation of the number of basic pension participants in each year during the forecast period. Referring to the methods of estimating the number of basic pension participants in the literatures (Chen and Yang [4]; Chen et al., [5]; Chen [6], etc.), the future population structure of China and the population structure of basic pension participants in the forecast period can be predicted respectively by using the queue element method.

Estimation of the remaining parameters. The State Council Document 38 in 2005 of "Decision on Improving the Basic Pension System for Urban Employees" stipulated that the individual contribution rate $c$ is $8 \%$. The age $(e)$ for employees to get their first job and participate in the basic old-age insurance is set at 22. The ultimate age $\omega$ of the insured person is set to 100 years old. With reference to Yang and Shi [1], the the growth rate of seniority wage $(s)$ is $1.363 \%$. Referring to Chen [6], the average annual salary of new recruits is 52512 yuan. The retirement age $(r)$ of employees is: the retirement age of male employees is 60 years old, and the retirement age of female employees is 55 years old. According to the monthly pension payment table of individual accounts in the State Council Document 38 in 2005 , we can get the number of months $m_{r}$ corresponding to retirement age $r$. With reference to the method of Yang and Shi [1], the future salary growth rate and bookkeeping rate of China can be set. The salary growth rate will be $7.7 \%$ from 2019 to $2020,6.6 \%$ from 2021 to 2025 and $5.7 \%$ from 2026 to 2030 , and keep $4.8 \%$ unchanged in other years. The bookkeeping rate is set at $3.27 \%$ in 2015 and before, and $7.83 \%$ in 2016 and later.

\section{ANALYSIS OF THE IMPACT OF THE COMPREHENSIVE TWO-CHILD POLICY}

With reference to the method of the previous studies (Yang and Shi [1]; Zhang et al., [12]; Chen [6]; etc.), the indicator of current pension balance $\left(B_{t}\right)$ is used to measure the financial status of individual accounts of the basic pension in China. The current balance $B_{t}$ is defined as pension contribution incomes $C_{t}-$ pension expenditures $P_{t}$.

The impact of the comprehensive two-child policy on individual accounts can be expressed as the change in balance $\left(\Delta B_{t}\right)$ during the forecast period. $\Delta B_{t}=B_{t}^{f r}-B_{t}^{O}$. The meaning of $B_{t}^{O}$ is the balance under the baseline scenario, that is, the total fertility rate in this scenario is 1.69 without considering the comprehensive two-child policy. The $B_{t}^{f r}$ means the balance calculated after considering the comprehensive two-child policy.

The five schemes that the comprehensive two-child policy will affect the total fertility rate from 2020 to 2095 can be divided into two categories. The first type is the scheme with a lower total fertility rate than the baseline total fertility rate of 1.69 , and there are two schemes, which are recorded as category $I$; the second type is the scheme with higher total fertility rate than the baseline total fertility rate of 1.69 , with a total of three schemes, which are recorded as category $I I$. The results of the five schemes are divided into two categories, as shown in Figure-2.

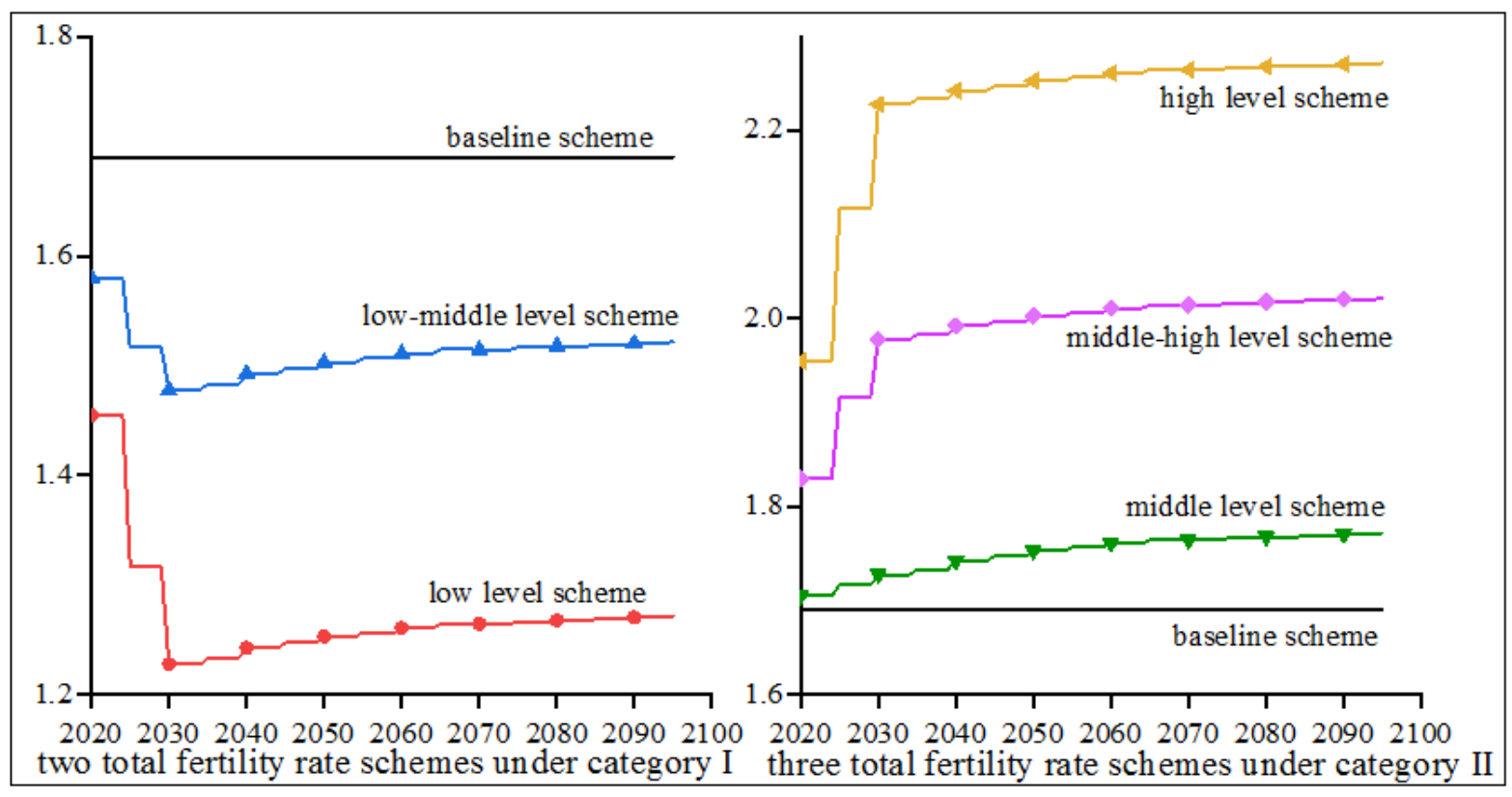

Fig-2: Two categories of total fertility rate schemes

According to the model of pension incomes and expenditures of individual accounts built in Section 3, combined with the above parameters, use MATLAB to program to calculate the contribution incomes under these five scenarios. Divide these schemes into two categories according to Figure 2, and compare the calculated results with the 
contribution incomes under the baseline situation, then we can get the effect of the comprehensive two-child policy on the contribution incomes of the individual accounts, as shown in Figure-3.

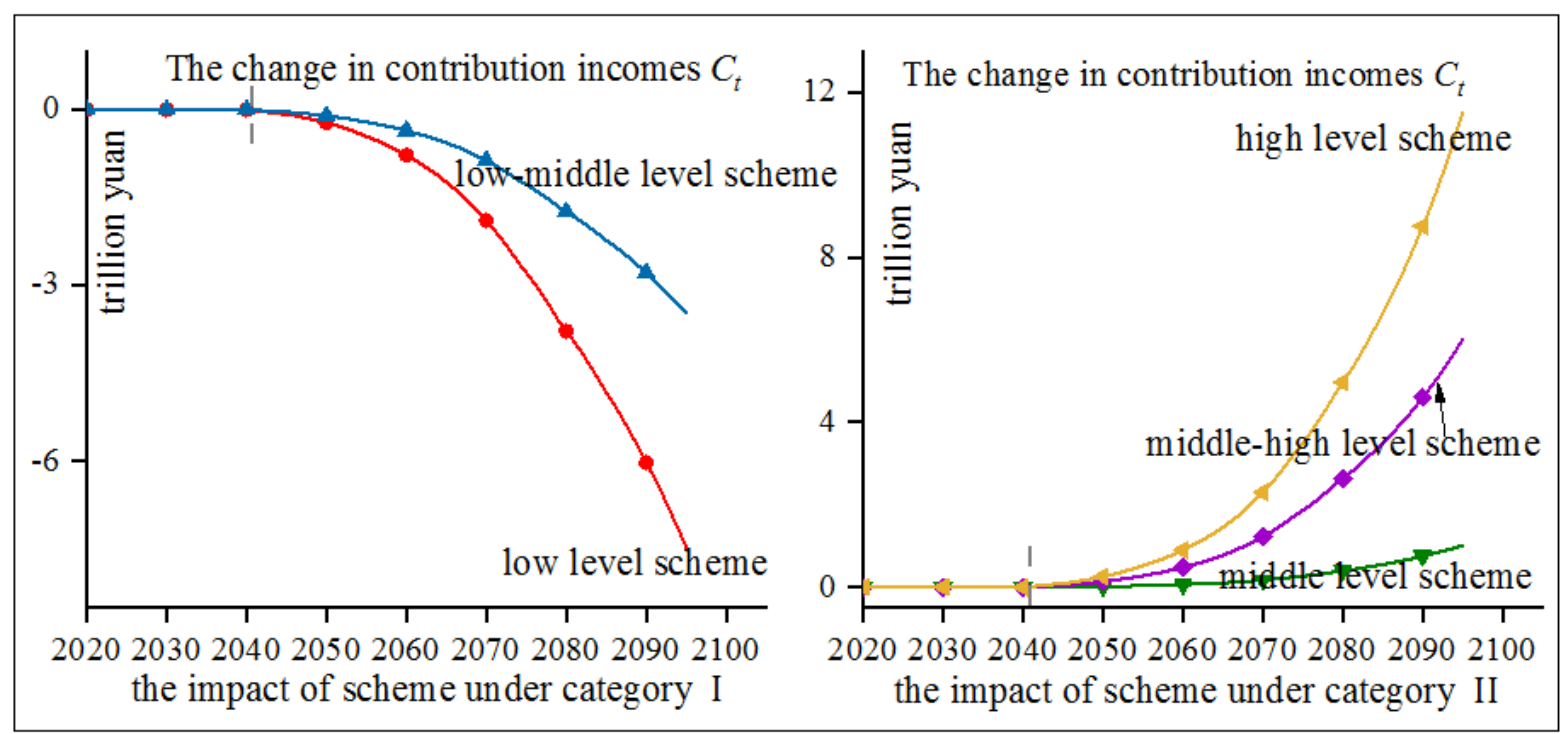

Fig-3: The impact of the policy on contribution incomes of the individual accounts

The comprehensive two-child policy has a delayed effect on the contribution incomes of the individual accounts, and it will not affect baisic pension incomes until 2041. If the comprehensive two-child policy reduces the total fertility rate in the forecast period from the baseline total fertility rate, such as the two total fertility rate schemes of category $I$, the contribution incomes of the individual accounts after 2041 is less than 0 compared with that in the baseline scheme, which indicates that the decline of the total fertility rate will reduce the contribution incomes of the individual accounts, and with the passage of the year, the stronger the effect of the policy on the decline of the contribution incomes. If the comprehensive two-child policy increases the total fertility rate in the forecast period compared with the baseline total fertility rate, such as the three total fertility rate schemes of category $I I$, the contribution incomes of the individual accounts after 2041 is greater than 0 compared with that in the baseline scheme, indicating that the increase in the total fertility rate will increase the contribution incomes of the individual accounts, and with the passage of the year, the stronger the effect of the policy on the increase of the contribution incomes.

Similarly, the effect of the comprehensive two-child policy on pension expenditures of individual accounts is shown in Figure-4.

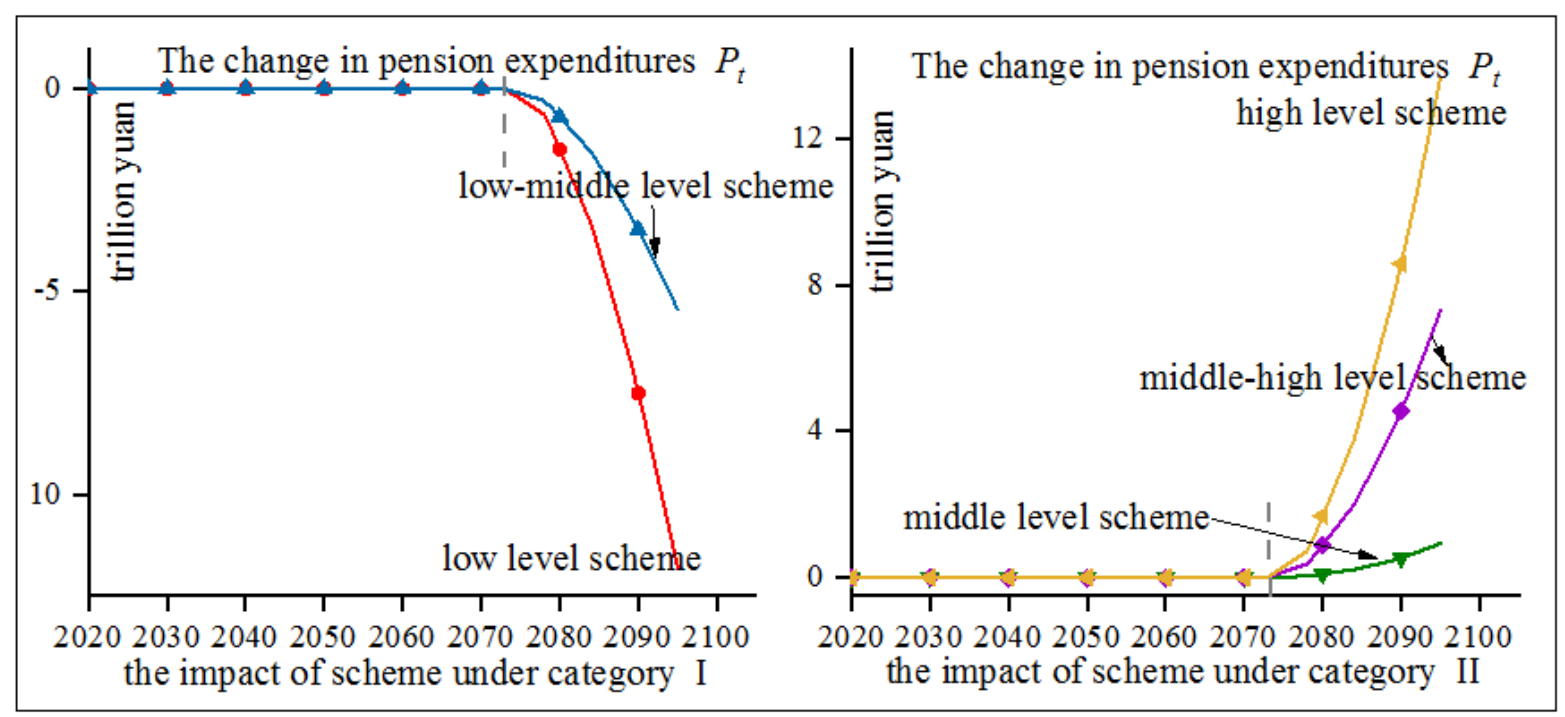

Fig-4: The impact of the policy on pension expenditures of the individual accounts 
It can be seen that the delayed effect of comprehensive two-child policy on pension expenditures is stronger than that of contribution incomes. The impact of the policy on pension expenditures will not affect the pension expenditures of individual accounts until 2074.

In the two total fertility rate schemes of category $I$, the pension expenditures of the individual accounts after 2074 is less than 0 compared with that in the baseline scheme, which indicates that the decline of the total fertility rate will reduce the pension expenditures of the individual accounts, and with the passage of the year, the stronger the effect of the policy on the decline of the pension expenditures. In the three total fertility rate schemes of category $I I$, the pension expenditures of the individual accounts after 2074 is greater than 0 compared with that in the baseline scheme, indicating that the increase in the total fertility rate will increase the pension expenditures of the individual accounts, and with the passage of the year, the stronger the effect of the policy on the increase of the pension expenditures.

Finally, by comparing the balance of individual accounts under the two categories of five total fertility rate schemes with the balance under the baseline scheme, we can get the impact of the comprehensive two-child policy on the individual accounts of China's basic pension, as shown in Figure-5.

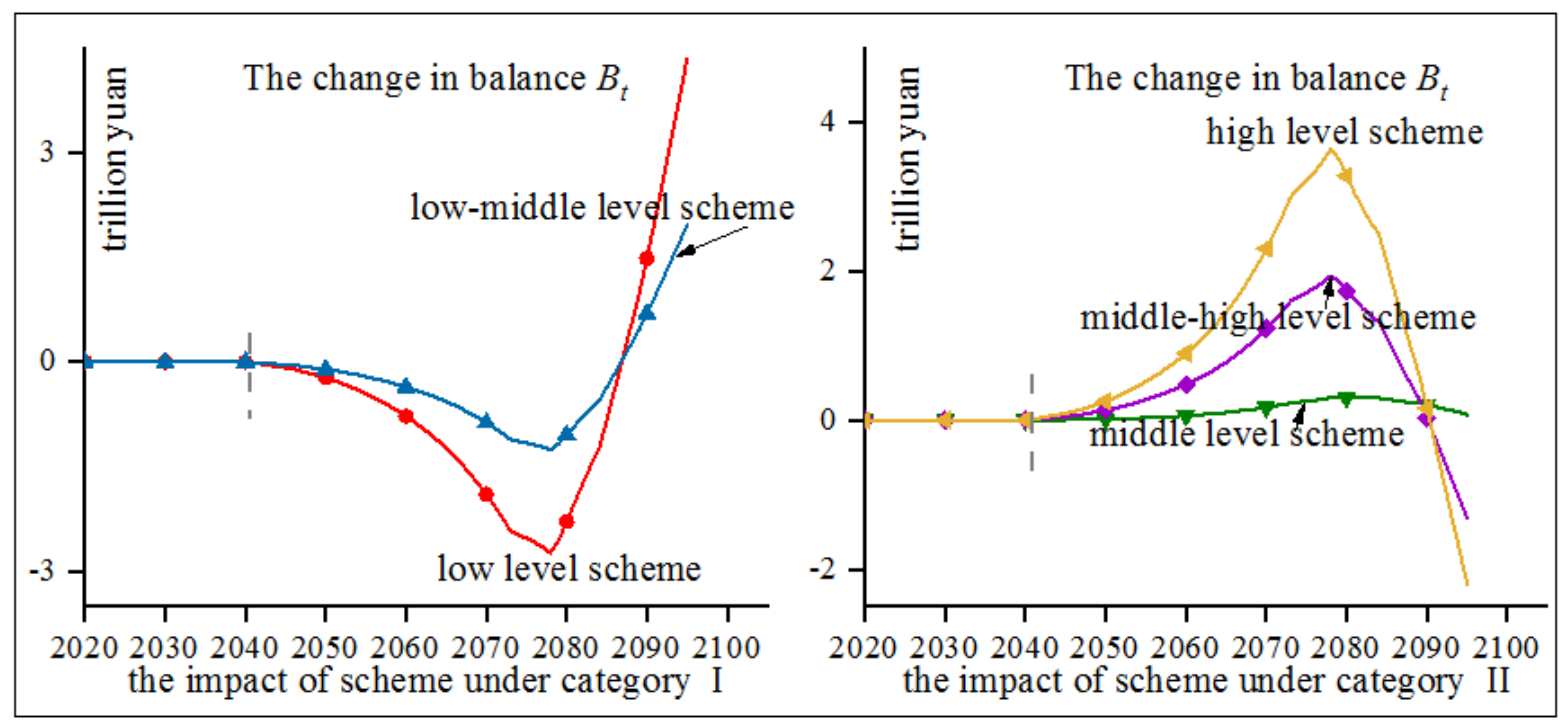

Fig-5: The impact of the policy on the balance of the individual accounts

The delayed effect of the comprehensive two-child policy on balance of individual accounts is the same as the delayed effect of contribution incomes, and it will not affect individual accounts' balance until 2041.

In the two total fertility rate schemes of category $I$, the balance of the individual accounts is less than zero compared with that in the baseline scheme in 2041-2087, and greater than zero compared with that in the baseline scheme in the years after 2087, which indicates that the decrease of the total fertility rate will reduce the balance of individual accounts between 2041 and 2087, and increase the balance in the year after 2087. In the three total fertility rate schemes of category II, the balance of individual accounts under the middle-high level scheme and the high level scheme is greater than zero compared with that in the baseline scheme in 2041-2091, and smaller than zero compared with that in the baseline scheme in the years after 2091, which indicates that the increase of the total fertility rate will increase the balance of individual accounts between 2041 and 2091, and decrease the balance in the years after 2091. What's more, the balance of the individual accounts under the middle level scheme is greater than zero compared with that in the baseline scheme in the forecast years after 2041, which will almost increase the balance of the individual accounts.

\section{ReSEARCH CONCLUSiOnS}

This research designs five possible schemes for China's total fertility rate affected by the comprehensive twochild policy, and explores the impact of the policy on the financial status of individual accounts of the basic pension in China. Referring to the experience of previous studies (Yang and Shi [1]; Chen and Yang [4]; Chen [6]; etc.), we construct an actuarial model of pension incomes and expenditures of individual accounts, and uses MATLAB software to simulate the impact of the comprehensive two-child policy. The research conclusions obtained are as follows.

1. The impact of the comprehensive two-child policy on the financial status of individual accounts has a time lag, and the earliest effective year of this policy is 2041 .

2. From the perspective of the comprehensive two-child policy that will increase China's total fertility rate in the 
future, the middle-high level scheme and the high level scheme will increase the balance of individual accounts in most periods after 2041, which is conducive to improving the sustainable operation ability of individual accounts. However, in the final five years of the forecast, the balance of the individual accounts will be reduced compared with that in the baseline scheme, which will increase the financial burden of the individual accounts. The middle scheme will increase the balance of individual accounts in the forecast year after 2041, which is conducive to improving the sustainable operation ability of individual accounts. Therefore, on the whole, if the comprehensive two-child policy increases China's future total fertility rate, the policy will help improve the sustainable operation of individual accounts in most years of the forecast period. And the mode of increasing the total fertility rate under the middle scheme will help improve the sustainable operation ability of individual accounts in the years after the policy works.

In view of the fact that the comprehensive two-child policy can basically improve the sustainable operation ability of the individual accounts of China's basic pension, the Chinese government should actively promote the implementation of the comprehensive two-child policy, and increase the total fertility rate to improve the sustainable operation ability of the individual accounts of China's basic pension.

\section{REFERENCES}

1. Yang, Z., \& Shi, C. (2016). Financial burden of pension in the pooling account of urban enterprise workers in China. Economic Science, 2:42-52.

2. Tian, Y., \& Zhao, X. (2016). Stochastic Forecast of the Financial Sustainability of Basic Pension in China. Sustainability, 8(1).

3. Zhao, Y., Bai, M., Feng, P., \& Zhu, M. (2018). Stochastic Assessments of Urban Employees' Pension Plan of China. Sustainability, 10(4).

4. Chen, X., \& Yang, Z. (2019). Stochastically Assessing the Financial Sustainability of Individual Accounts in the Urban Enterprise Employees' Pension Plan in China. Sustainability, 11(13).

5. Chen, X., Zhong, S., \& Qi, T. (2020). Delaying Retirement and China's Pension Payment Dilemma: Based on a General Analysis Framework. IEEE Access, 8:126559-126572.

6. Chen, X. (2020). Delaying Retirement and Individual Account Finance of China's Basic Pension Insurance, South Asian Research Journal of Business and Management, 2(4):92-98.

7. Luo, Z., Chen, Z., \& Lu, A. (2010). A Study on the Effects of Population Factors on the Payment Balance of Basic Pension Insurance Funds in China, Forecasting, 2:42-46.

8. Sun, B., Dong, K., \& Tang, Y. (2011). Research on the Impact of the Adjustment of Fertility Policy on the Basic Pension Gap, Population \& Economics, 2:101-107.

9. Zeng, Y., Ling, Y., \& Zhang, X. (2016). From Selective Two-child Policy to Universal Two-child Policy: Can the Sustainability of China's Basic Pension Insurance Fund for Urban and Rural Residents Be Improved, Public Finance Research, 11:65-79+64.

10. Xiao, C., \& Deng, D. (2017). A Study on the Impact of "Total Two-Child” Policy on the City Staff Basic Pension's Public Funds Expenditure Ability, Journal of Guizhou University of Finance and Economics, 3:15-24.

11. Li, X., \& Luo, S. (2018). Financial Stress Estimation and Policy Study of Shanghai Pension Fund for Urban Employees under the Universal Two-Child Policy, Public Finance Research, 8:105-120.

12. Zhang, X., Zeng, Y., Shi, C., \& Liu, T. (2018). Fiscal responsibility assessment of basic pension insurance for urban employees from a sustainable perspective-re-examination on the effect of universal two-child policy and delaying retirement policy. Public Finance Research, 12:97-113. 